\title{
The Influence of Irradiation and Accelerated Aging on the Mechanical and Tribological Properties of the Graphene Oxide/Ultra-High-Molecular-Weight Polyethylene Nanocomposites
}

\author{
Guodong Huang, Zifeng Ni, Guomei Chen, and Yongwu Zhao \\ School of Mechanical Engineering, Jiangnan University, Wuxi, Jiangsu 214122, China \\ Correspondence should be addressed to Zifeng Ni; nizf@jiangnan.edu.cn and Yongwu Zhao; zhaoyw@jiangnan.edu.cn
}

Received 28 June 2016; Accepted 11 August 2016

Academic Editor: Yin Chen

Copyright (C) 2016 Guodong Huang et al. This is an open access article distributed under the Creative Commons Attribution License, which permits unrestricted use, distribution, and reproduction in any medium, provided the original work is properly cited.

\begin{abstract}
Graphene oxide/ultra-high-molecular-weight polyethylene (GO/UHMWPE) nanocomposite is a potential and promising candidate for artificial joint applications. However, after irradiation and accelerated aging, the mechanical and tribological behaviors of the nanocomposites are still unclear and require further investigation. GO/UHMWPE nanocomposites were successfully fabricated using ultrasonication dispersion, ball-milling, and hot-pressing process. Then, the nanocomposites were irradiated by gamma ray at doses of $100 \mathrm{kGy}$. Finally, GO/UHMWPE nanocomposites underwent accelerated aging at $80^{\circ} \mathrm{C}$ for 21 days in air. The mechanical and tribological properties of GO/UHMWPE nanocomposites have been evaluated after irradiation and accelerated aging. The results indicated that the incorporation of GO could enhance the mechanical, wear, and antiscratch properties of UHMWPE. After irradiation, these properties could be further enhanced, compared to unirradiated ones. After accelerated aging, however, these properties have been significantly reduced when compared to unirradiated ones. Moreover, GO and irradiation can synergistically enhance these properties.
\end{abstract}

\section{Introduction}

Ultra-high-molecular-weight-polyethylene (UHMWPE) is considered as being suitable bearing materials for orthopedic implants [1] because it has excellent properties including good wear resistance, exceptional toughness, a lower friction coefficient, and good biocompatibility [2]. However, during the long-term application process, wear, oxidation, and wear debris accumulation easily result in osteolysis [3] and aseptic loosening [4, 5]. And it ultimately leads to failure of orthopedic implants. In order to increase the longevity of orthopedic implants, much effort has been placed on improving mechanical and tribological properties of UHMWPE. Among most of methods, gamma-irradiation and UHMWPE-based composites are two main methods.

Gamma-irradiation is the usual method for enhancing polymer properties, which not only provides reliable and effective medical sterilization but also can cross-link the polymer. The free radicals are generated during gammairradiation through the scission of $\mathrm{C}-\mathrm{H}$ and $\mathrm{C}-\mathrm{C}$ bonds. In the one aspect, free radicals produced by irradiation can form crosslinking by recombining each other in the amorphous phase of polyethylene. As a consequence, wear properties of UHMWPE have been significantly improved [6]. In the other aspect, in crystalline phase of polyethylene, residual free radicals can react with oxygen and result in oxidation degradation of UHMWPE during shelf aging or after implantation $[7,8]$, which greatly affect mechanical and tribological properties. Therefore, accelerated aging methods are used to evaluate potential for long-term oxidation resistance of the polymer in air. It is crucial for long-lasting artificial joint to understand the influence of irradiation and long-term shelf aging in air on the oxidation of UHMWPE.

In addition to gamma-irradiation, another alternative method is UHMWPE-based composites. Various fillers such 
as Graphene [9-11], carbon nanotubes (CNTs) [12], graphite, calcium carbonate $\left(\mathrm{CaCO}_{3}\right)$ [13], and wollastonite [14] have been applied to enhance mechanical and antiwear properties of the polymer. Among the above fillers, Graphene is regarded as an ideal reinforcing filler due to its superior mechanical [15] and lubricant properties [16]. However, it is difficult to disperse Graphene in the polymer matrix [17]. As a result, Graphene oxide (GO), which is one of the most important Graphene derivatives, has been widely used to enforce polymer properties due to excellent dispersion in polymer matrix. The incorporation of GO into UHMWPE can significantly improve antiwear and mechanical properties of UHMWPE. For instance, GO/UHMWPE nanocomposites can enhance the hardness, tensile strength, and impact strength of UHMWPE [18-20]. And GO can reduce the wear rate but increase mean friction coefficient of UHMWPE $[21,22]$. Moreover, it is also found that the optimum $0.5 \mathrm{wt} \%$ GO content for the nanocomposites can effectively improve GO/UHMWPE nanocomposites performance, compared to pure UHMWPE [23]. Although these important results give important insights into GO/UHMWPE nanocomposites, the influence of gamma-irradiation and accelerated aging on antiwear and mechanical properties of GO/UHMWPE nanocomposites has rarely been reported. In this paper, the mechanical and tribological properties of GO/UHMWPE nanocomposites are studied after gamma-irradiation and accelerated aging.

\section{Experimental Details}

2.1. Sample Preparation Method. UHMWPE powder with a density of $0.93 \mathrm{~g} / \mathrm{cm}$ has a molecular weight of approximately 5 million. GO is prepared via the modified Hummer's methods [24]. GO/UHMWPE composites with $0.5 \mathrm{wt} \% \mathrm{GO}$ loading are prepared by following route reported by previous work [25]. In brief, $0.5 \mathrm{~g}$ GO powder is dispersed in $200 \mathrm{~mL}$ alcohol solution and sonicated for $30 \mathrm{~min}$. Then, $99.5 \mathrm{~g}$ UHMWPE powder is dispersed in GO solution and sonicated for another $40 \mathrm{~min}$. Next, the mixture solution is kept in an oven at $60^{\circ} \mathrm{C}$ until the solvent is completely volatilized. Subsequently, dried powder composites are ball-milled for $2 \mathrm{~h}$ at the constant rotation rate of $400 \mathrm{rpm}$. Afterward, the powder composites are prepressed in the model at $15 \mathrm{MPa}$ for $15 \mathrm{~min}$. Then pressed powder composites are heated for $2 \mathrm{~h}$ at $200^{\circ} \mathrm{C}$ in an air oven. Finally, the powder composites taken out from an air oven are pressed at $10 \mathrm{MPa}$ until their temperature cools to room temperature.

Vacuum-packed samples are irradiated at room temperature by ${ }^{60}$ Co gamma-rays (WuXi EL PONT Radiation Technology Co., Ltd.) with irradiation doses of $100 \mathrm{kGy}$.

Accelerated aging process is carried out at $80^{\circ} \mathrm{C}$ for 21 days in an air oven (according to ASTM F2003-00; ASTM: American Society for Testing and Materials).

The morphology of the surface is observed by Hitachi's S-4800 field emission scanning electron microscopy (SEM).

2.2. Mechanical Properties. The test samples are cut into dumbbell-shaped test specimens according to the ASTM

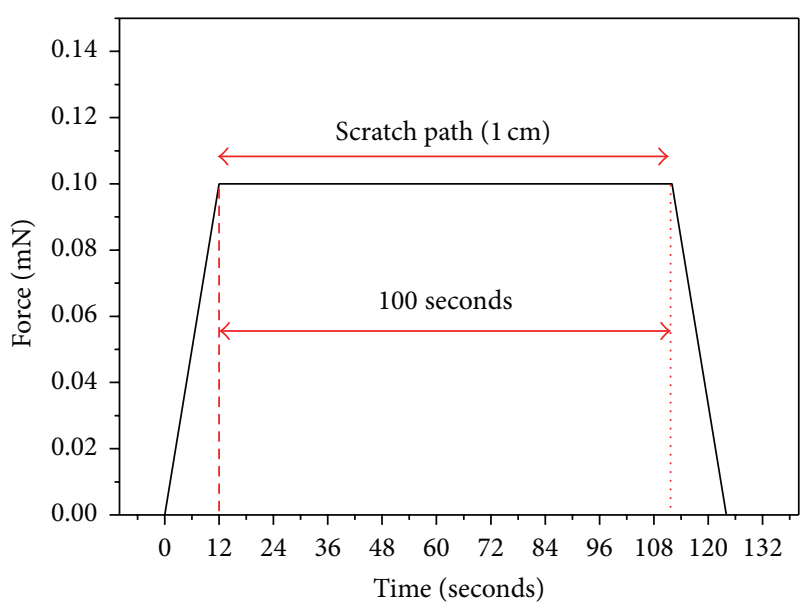

FIGURE 1: The loading-unloading curve in scratching process.

D638 (Type IV; thickness: $3.2 \mathrm{~mm}$ ). Tensile tests are performed on a tensile machine (WDW-200, Jinan Shijin Group Co. Ltd., China) at the crosshead speed of $50 \mathrm{~mm} / \mathrm{min}$. At least five specimens are tested for each case. Young's modulus, yield stress, and fracture stress are calculated according to the stress-strain curves.

The ball indentation hardness is measured according to the ISO2039-73 $[26,27]$ as a referee and the measurements are carried out with Rtec Tribometer (Type: MFT-5000; Rtec Instruments, Inc., USA). The indenter is a $\mathrm{Si}_{3} \mathrm{~N}_{4}$ ball of $5 \mathrm{~mm}$ in diameter. The initial applied preload is $9.8 \mathrm{~N}$ and the applied test load is $132 \mathrm{~N}$. The measured hardness $H$ can be calculated according to the following equation [27]:

$$
H=\frac{P_{\max }}{\pi D h_{\max }},
$$

where $P_{\max }$ is the test force, $D$ is the diameter of the ball, and $h_{\max }$ is the reduced depth of the impression.

2.3. Scratching Test. Scratching testing is performed with Rtec Tribometer (Type: MFT-5000; Rtec Instruments, Inc., USA). Conical diamond tip $\left(1 \mathrm{~mm} \times 5 \mathrm{~mm} \times 60^{\circ}, 12.5\right.$ micron diamond radius) is used to scratch the surface of the samples. The loading-unloading curve is shown in Figure 1. In scratching process, the applied constant load is $0.1 \mathrm{~N}$; the scratch velocity is about $10 \mathrm{~mm} / \mathrm{s}$ and the scratch length is set at $10 \mathrm{~mm}$. The residual depth of the scratch is measured by Rtec Profilometer (Type: MFD-D; Rtec Instruments, Inc., USA). The friction coefficient $(\mu)$ is calculated according to the following equation:

$$
\mu=\frac{F_{T}}{F_{N}},
$$

where $F_{N}$ is normal force and $F_{T}$ is lateral force. Scratch causing wear resistance of test samples is assessed by measuring the volume loss by Rtec Lambda view (Rtec Instruments, Inc., USA). 


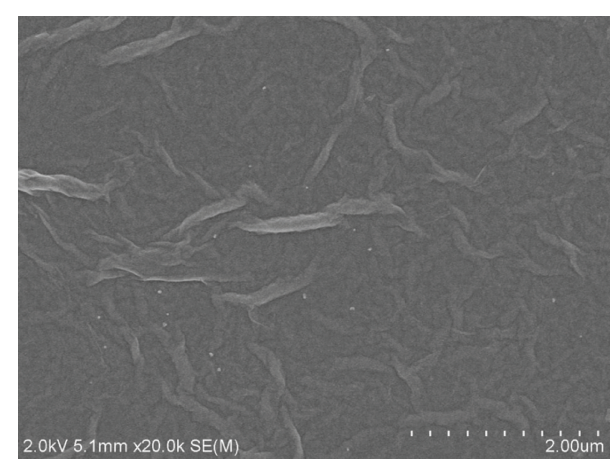

(a)

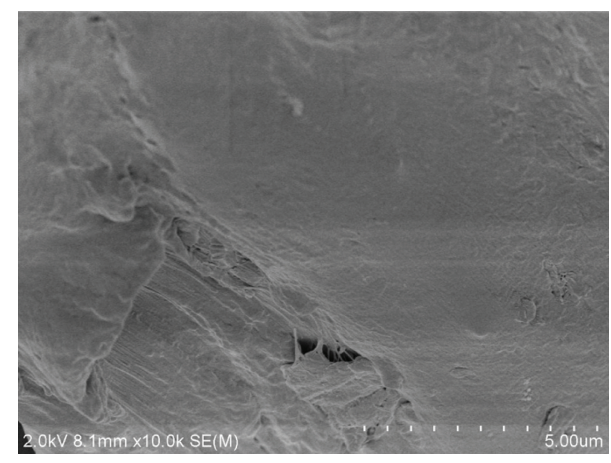

(b)

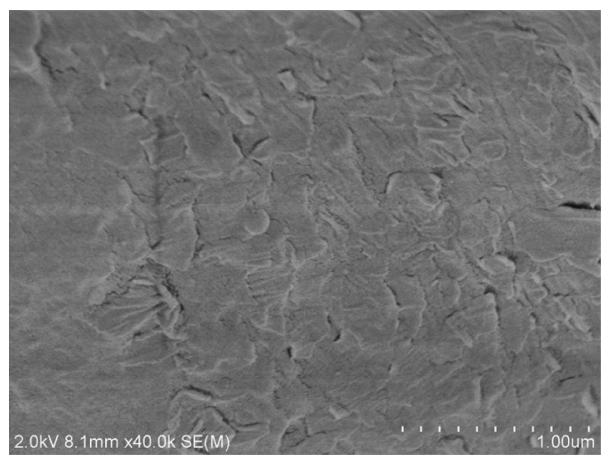

(c)

FIGURE 2: The SEM images of (a) GO, (b) UHMWPE, and (c) GO/UHMWPE composites.

\section{Results and Discussion}

3.1. Surface Topography. The SEM image of GO (Figure 2(a)) displays the rough and wrinkled morphology. The surface topography of UHMWPE and GO/UHMWPE composites is shown in Figures 2(b) and 2(c), respectively. It can be clearly seen from SEM images that incorporation of GO into UHMWPE matrix has a dramatic influence on the surface topography of UHMWPE. In comparison with UHMWPE, GO/UHMWPE composites show uneven surface because crumpled and wrinkled GO sheets are dispersed in the interface of the composites. The wrinkled rough surface of GO can result in a stronger interfacial adhesion between $\mathrm{GO}$ and polymer matrix [28]. GO possesses much oxygencontaining polar functionalities, such as hydroxyl, carbonyl, epoxide, and carboxyl groups, which make it more versatile in interacting with various polymers [29]. The stronger interfacial adhesion is beneficial to stress transfer between GO and polymer matrix [30], which can significantly influence the mechanical and tribological properties of UHMWPE.

3.2. Mechanical Properties. The mechanical properties measured are Young's modulus, yield stress, fracture stress, and hardness, which are shown in Figure 3. The results indicate that GO, irradiation, and accelerated aging significantly affect the mechanical properties of test samples.

The nanocomposites with lower GO loading can offer significant improvement in mechanical properties. Young's modulus, yield stress, fracture stress, and hardness of GO/UHMWPE composites are increased by $22.44 \%$, $8.10 \%, 42.53 \%$, and $44.32 \%$, respectively, compared to pure UHMWPE. These mechanical behaviors of typical $\mathrm{GO} /$ polymer systems have been reported in previous studies $[18-20,23]$. The improved mechanical properties of the composites can be attributed to strong interfacial adhesion between GO and UHMWPE matrix, which plays a crucial role in mechanical performance of polymer-GO composites [15]. In GO/UHMWPE composites, van der Waals interaction plays an important role among GO and UHMWPE matrix and consequently GO affects UHMWPE response to tensile loading. Wrinkled GO, tightly adhering on the interface of UHMWPE, can result in interface roughness which may likely lead to an enhanced mechanical interlocking and adhesion with the polymer chains [29]. Moreover, GO contains a range of hydrophilic functionalities on its basal planes and carbon edges, which can enhance compatibility with polymer matrix. Consequently, interfacial forces are transferred efficiently from the polymer matrix to reinforcement [31].

Irradiation further enhances mechanical properties of the composites. Young's modulus, yield stress, fracture stress, and hardness of irradiated composites are increased by $17.22 \%, 11.66 \%, 19.50 \%$, and $13.25 \%$, respectively, compared to unirradiated composites. The similar change trends have been observed in irradiated UHMWPE/MWNT nanocomposites [32]. The mechanical properties of the composites depend directly on the crystallinity [33]. During irradiation in vacuum, free radicals are formed due to the cleavage of 


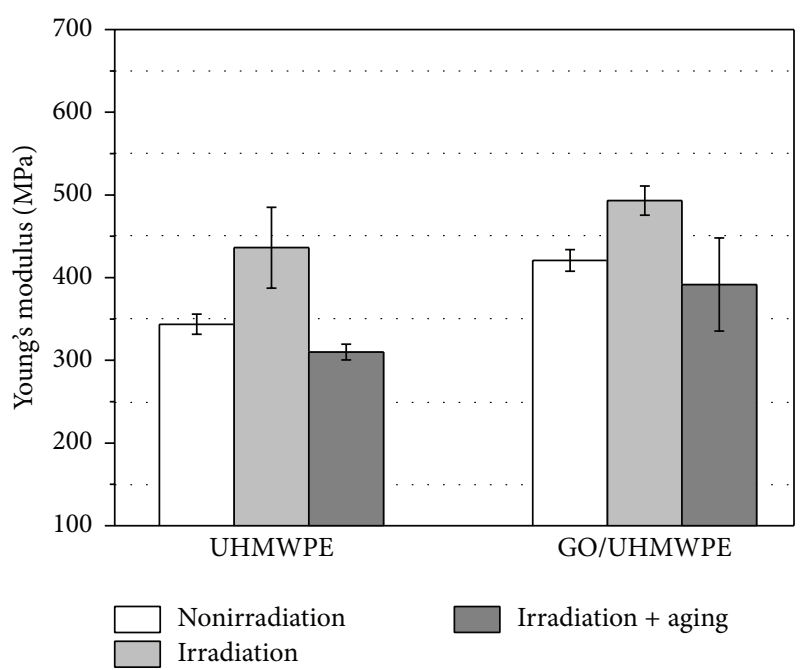

(a)

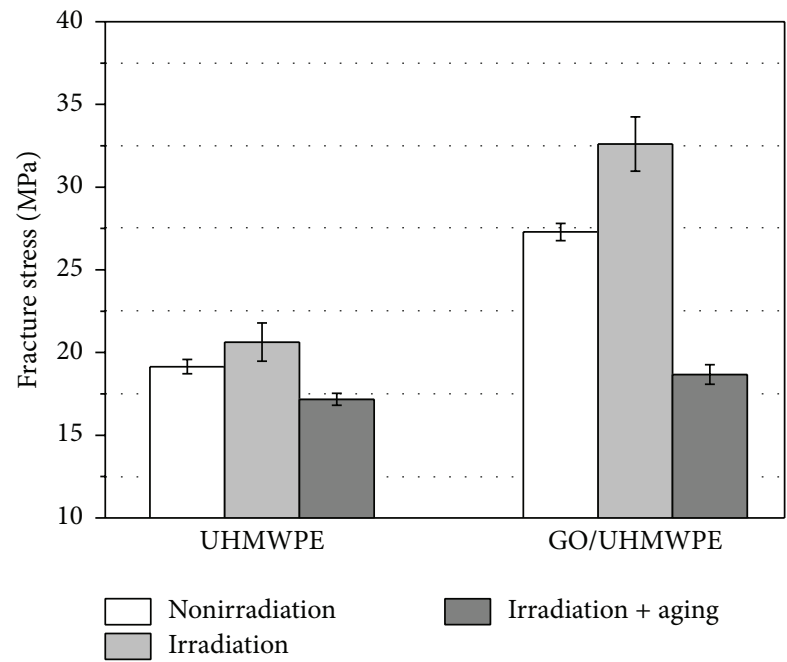

(c)

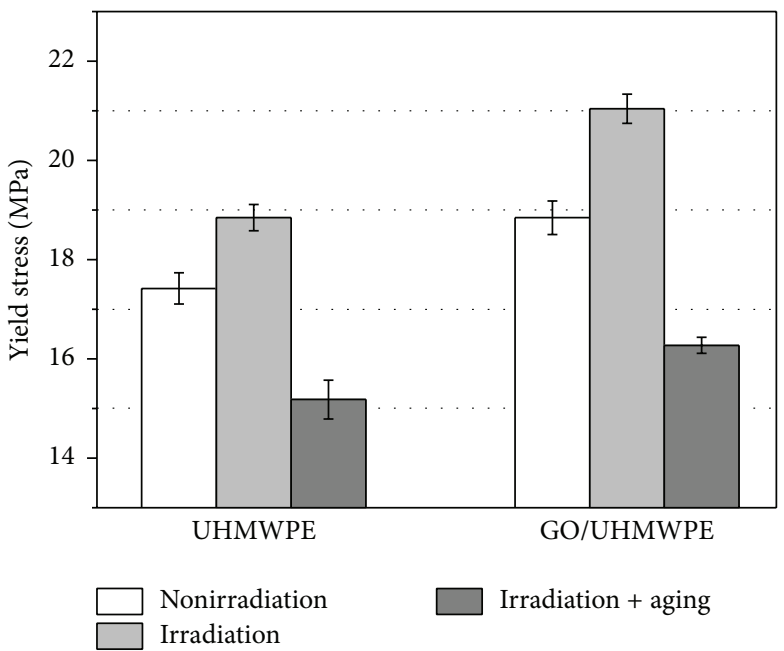

(b)

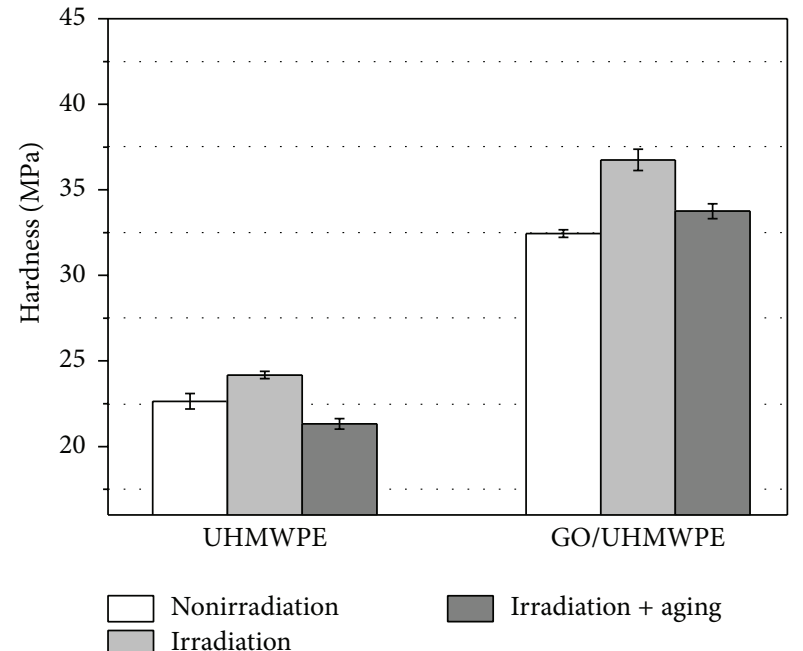

(d)

FIGURE 3: Mechanical properties: (a) Young's modulus; (b) yield stress; (c) fracture stress; (d) hardness.

$\mathrm{C}-\mathrm{C}$ and $\mathrm{C}-\mathrm{H}$ bond and can recombine with each other to form crosslinking which results in the enhancement of the crystallinity of UHMWPE. According to our previous studies [25], irradiation can significantly increase the crystallinity of GO/UHMWPE composites. Moreover, irradiation can cause bond scission in GO and produce dangling bonds [34] which can create molecular bond with matrix. Recently, it has been reported that GO was very weak radicals scavenger [35]. It may be proposed that few free radicals in UHMWPE may bond with GO. Consequently, irradiation may result in the stronger GO/matrix interaction. Therefore, irradiated composites obtain better mechanical properties than nonirradiated composites. Moreover, GO and irradiation can synergistically enhance the mechanical performance of UHMWPE. These similar results have been reported in irradiated MWCNTs/UHMWPE [32].
However, accelerated aging leads to a significant decrease in mechanical properties of the samples. Young's modulus, yield stress, fracture stress, and hardness of aged composites are reduced by $20.58 \%, 22.66 \%, 42.75 \%$, and $8.16 \%$, respectively, compared to irradiated composites. And Young's modulus, yield stress, fracture stress, and hardness of aged UHMWPE are reduced by $28.91 \%, 19.45 \%, 20.14 \%$, and 11.78, respectively, compared to irradiated UHMWPE. After accelerated aging, the reduced mechanical properties are attributed to oxidative degradation of thermal. When the samples undergo accelerated aging, high temperature accelerates oxygen diffusion in the interior of UHMWPE and the migration of free radicals in the crystallinity phase of UHMWPE, which greatly increases the reaction probability of oxygen with free radicals. As a consequence, accelerated oxidative degradation produces a great deal of ketone, 


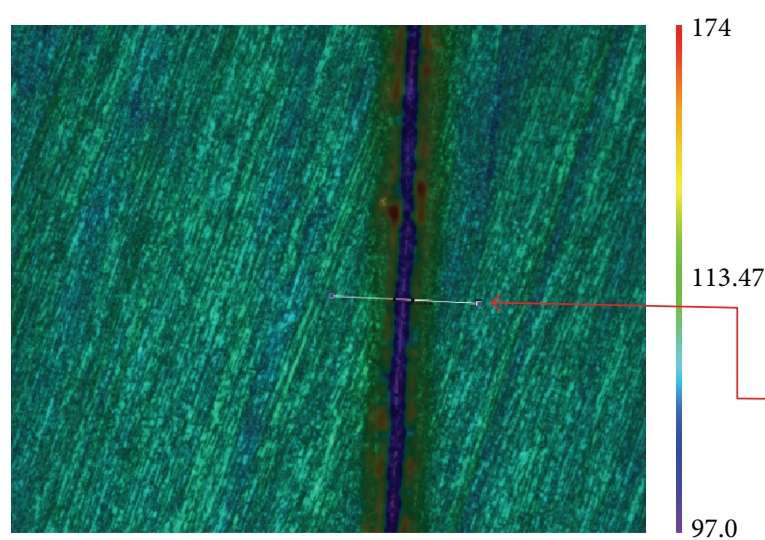

(a)

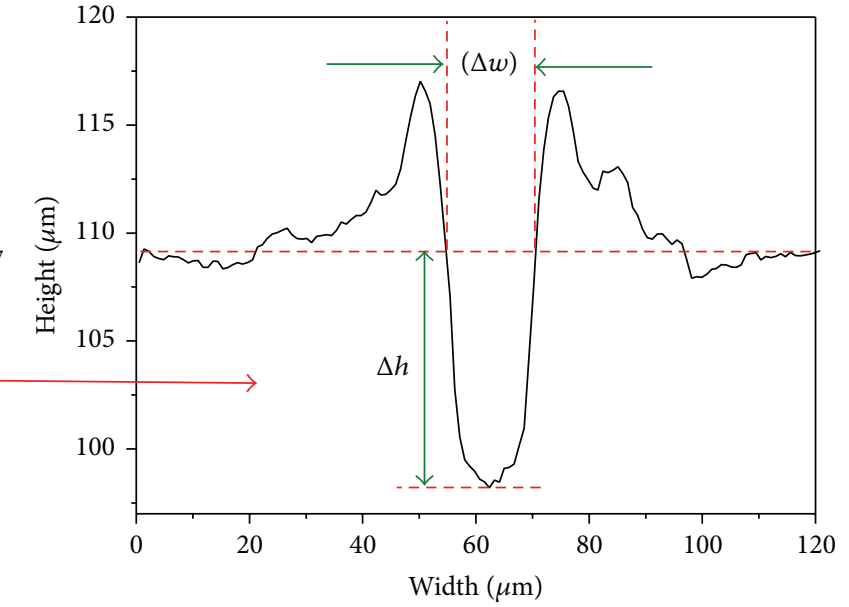

(b)

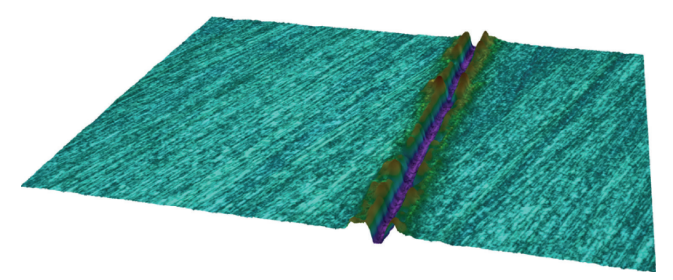

(c)

Figure 4: (a) 2D image of the scratch. (b) Width and depth profile through the scratch on the test sample. (c) 3D image of the scratch.

alcohol, carboxylic acids, and esters, finally resulting in degradation of mechanical properties of the samples. According to Figure 3, it is also observed that GO cannot restrict the aging degradation of the mechanical properties of UHMWPE. Although GO shows the capacity of scavenging free radicals [35], GO may display a very weak radical scavenging activity in GO/UHMWPE composites, resulting in poor antioxidant capacity [25]. Therefore, the mechanical properties of the composites have been greatly reduced during accelerated aging.

3.3. Tribological Properties. The scratch technique is extensively applied to evaluate the frictional, wear, and scratch resistance characteristics of polymer composites under specified conditions [36]. A diamond tip is pressed on the surface of the samples and then drawn on the surface under a constant force and with a constant velocity. As a typical scratched surface is shown in Figure $4, \Delta h$ is mean scratch depth.

In scratching process, the coefficients of friction (COF) are calculated based on (2). Figures 5(a) and 5(b) show the variations of the COF values of different samples. The results indicate that the incorporation of GO shows a slight increase in COF values of GO/UHMWPE nanocomposites, compared to the samples without adding GO. In comparison with unirradiation samples, irradiation further increases the $\mathrm{COF}$ of the samples. However, accelerated aging produces a marked decrease in the COF of the samples.

GO is considered as a good candidate for solid lubricants, which can reduce the adhesion and friction force between the contact surfaces [37]. However, in our experiments, it seems that GO does not display lubricant properties because of a slight increase in the COF, when GO is added into UHMWPE matrix. The similar results have been found by Tai et al. [22] The reason can be attributed to increased lateral force. The additional lateral force encountered by a diamond tip during travel inside the GO/UHMWPE composites consists of three aspects: GO-UHMWPE bond; GO-GO interlayer van der Waals bonds; and C-C bond in GO plane. Moreover, wrinkled GO sheets can make wrinkled or rough surface and enhance mechanical properties of UHMWPE. As a consequence, the $\mathrm{COF}$ of the composites has a slight increase.

After irradiation, the increased COF can be attributed to the crosslinking and chain-reorganization. Free radicals induced by irradiation recombine each other, resulting in chain-reorganization. Crosslinking restricts the mobility of molecular chains in the amorphous region and decreases the creep behavior of UHMWPE. Furthermore, irradiation affects structural integrity and mechanical properties of UHMWPE. Consequently, the plastic property has a reduction and the hardness has been increased, which may result in an increase in the lateral force.

Aging leads to oxidative degradation of polymer composites, which efficiently embrittles the surface and significantly reduces mechanical performance of polymer composites. Aged composites include much shorter chains and have weaker bonding between polymer matrix and the dispersed fillers, compared to unaged polymer composites. Thus, debonding and cracking in the scratch process can be more easily caused in oxidized dominant region of the scratched 


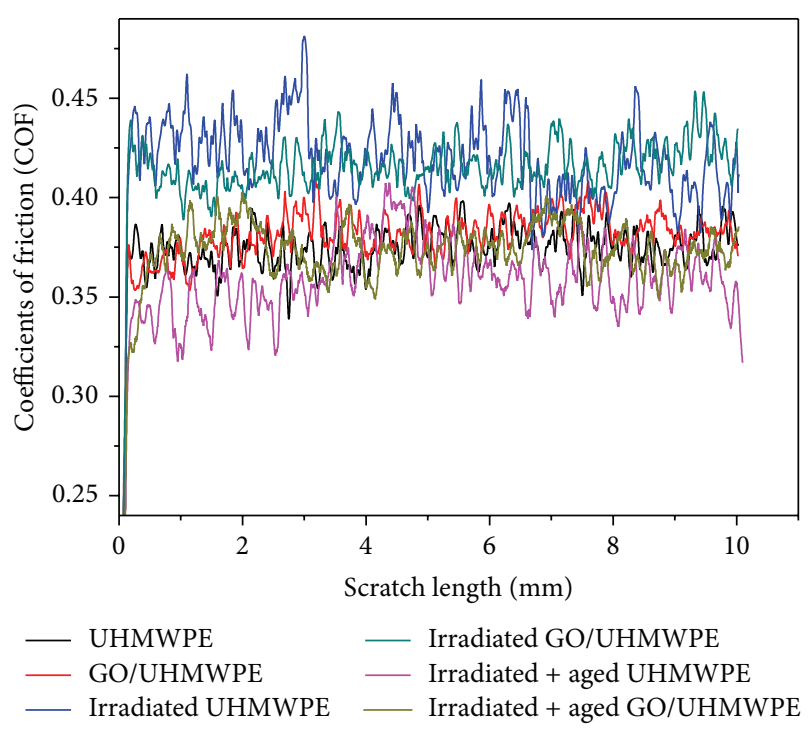

(a)

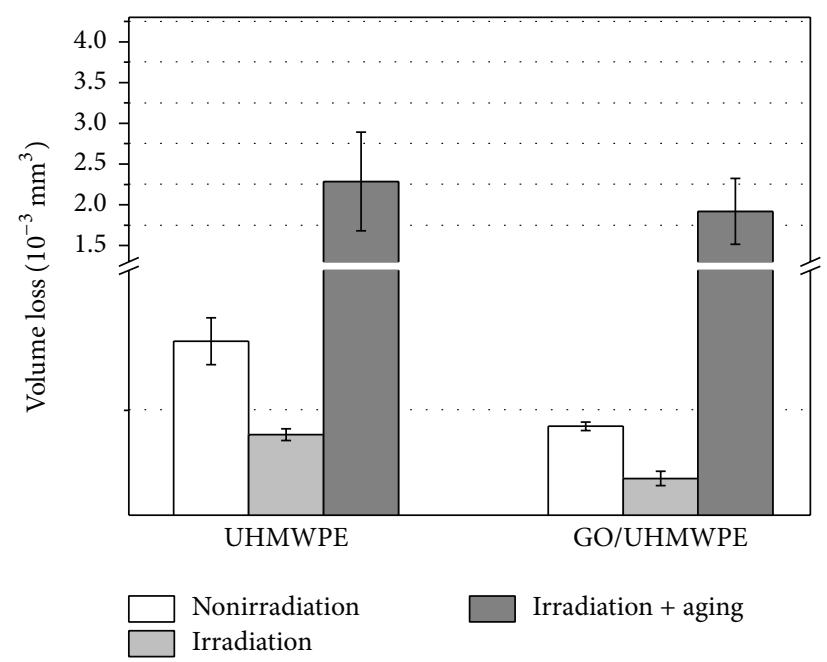

(c)

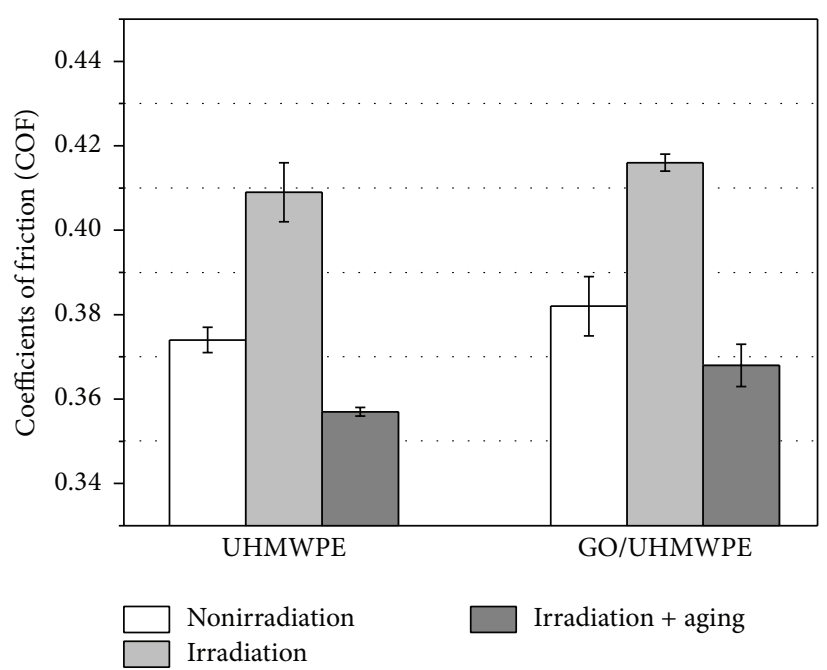

(b)

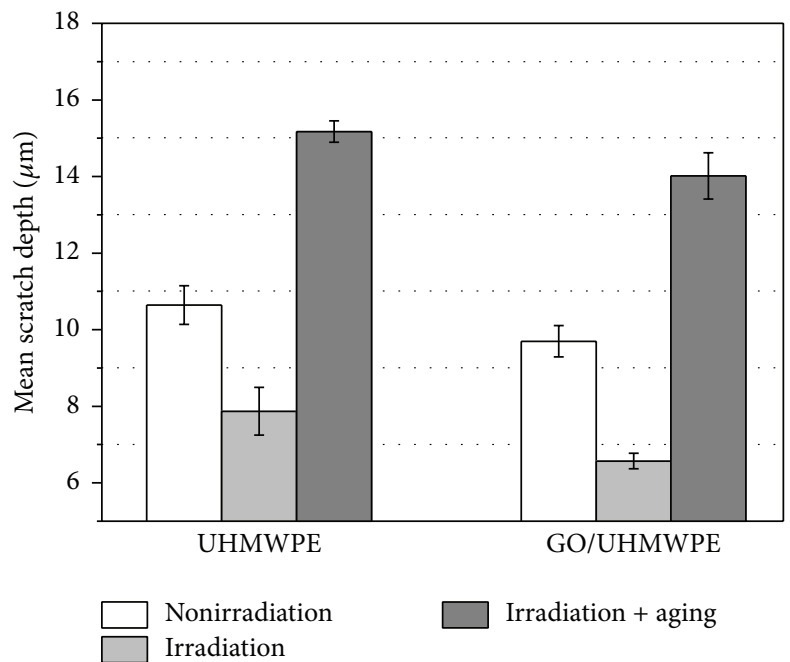

(d)

Figure 5: ((a), (b)) Coefficients of friction (COF) of test samples. (c) Wear rate of test samples. (d) Mean scratch depth.

subsurface. Consequently, the COF of aged composites has a slight reduction.

The wear volume losses induced by scratch are adopted to evaluate wear resistance properties. The variations of wear volume of all samples are shown in Figure 5(c). The incorporation of GO can improve wear resistance and irradiation further improves wear resistance. However, accelerated aging reduces wear resistance. Comparing wear rate and mechanical properties, it is found that wear rate has a relation with mechanical properties. The wear protection of GO can be attributed to increased mechanical strength and hardness [16]. Irradiation can further increase wear resistance of the composites due to crosslinking. Crosslinking induced by irradiation can increase the wear resistance of UHMWPE by improving the crossing-path motion. Moreover, crosslinking can efficiently restrict chain slippage and make UHMWPE more resistant to being drawn into fibrils [38]. However, after aging, oxygen degradation can break down the crosslinking and decrease wear resistance while further resulting in reducing mechanical properties.

Figure 5(d) summarizes mean residual depth of the scratch. Adding GO can significantly reduce scratch depth, compared to the samples without adding GO. Irradiation can further decrease residual depth, compared to unirradiated samples. In comparison to GO and irradiation, accelerated aging produces a marked increase of residual depth. Figure 6 shows optical scratching images of test samples. The shallower scratch grooves without fracture are observed from all samples. After accelerated aging, subsurface lateral cracking results in chipping (see Figures 6(e) and 6(f)).

In general, the scratch depth is important microstructure parameters to evaluate scratch resistance $[39,40]$. Moreover, the surface deformation is strongly affected by mechanical properties, ductility, and modulus [41]. So, the materials with 


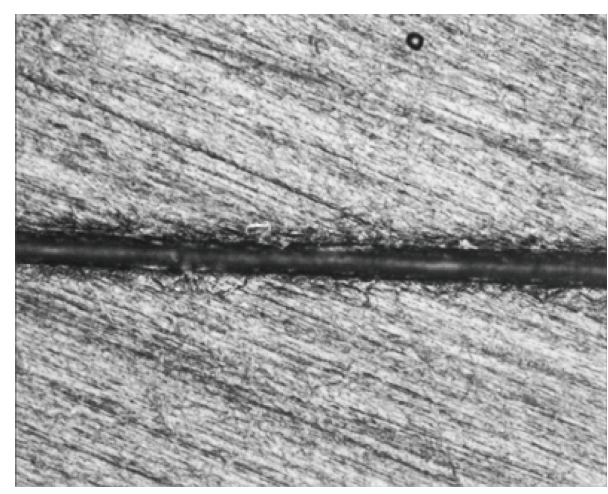

(a)

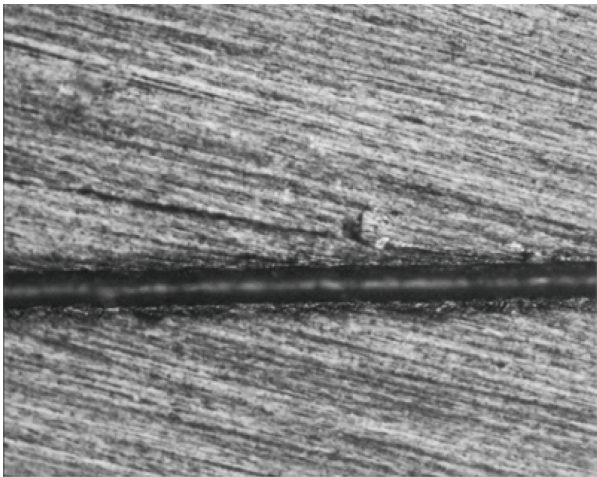

(c)

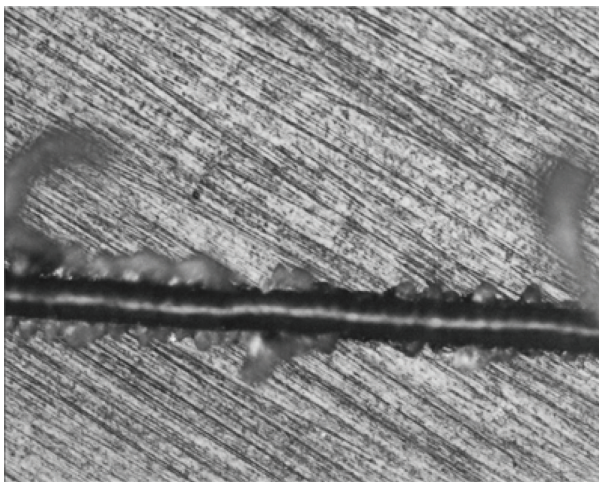

(e)

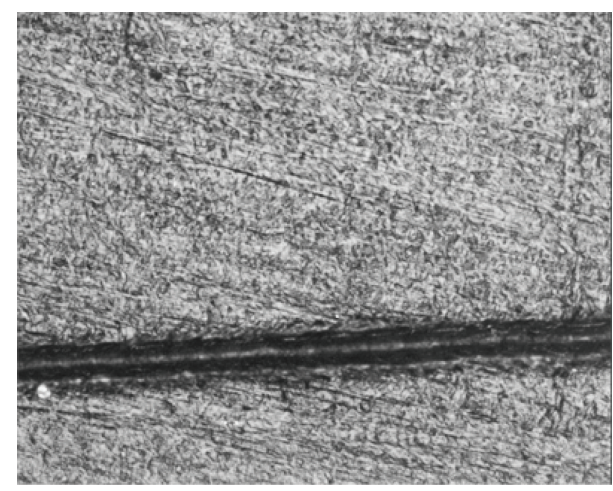

(b)

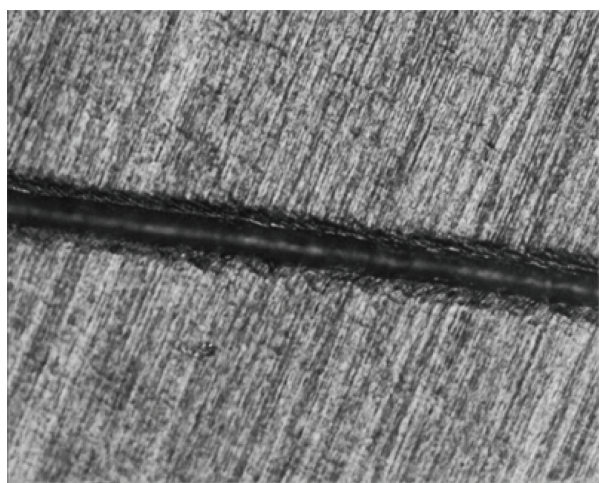

(d)

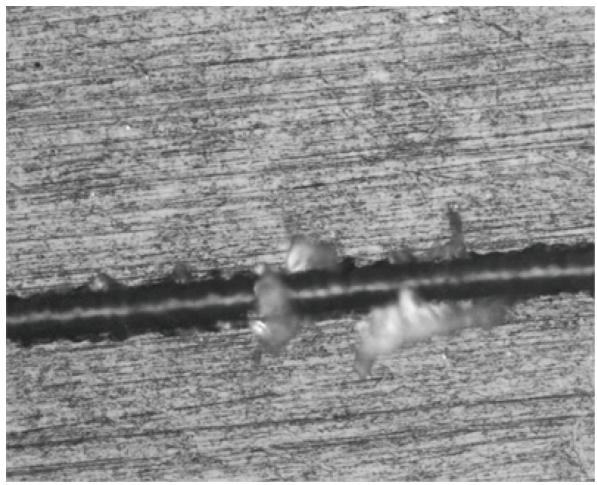

(f)

FIgURE 6: Optical scratching images of test samples (×20): (a) UHMWPE; (b) GO/UHMWPE nanocomposites; (c) irradiated UHMWPE; (d) irradiated GO/UHMWPE nanocomposites; (e) irradiated + aged UHMWPE; (f) irradiated + aged GO/UHMWPE nanocomposites.

excellent mechanical properties may display high scratch resistance. Adding GO can efficiently improve scratch resistance of UHMWPE. The reason is that the incorporation of GO into UHMWPE can increase the crystallinity [20], modulus, and yield stress. Similar results were observed in $\mathrm{GO} /$ polypropylene nanocomposites [42]. Irradiation further enhances scratch resistance of the samples because irradiation further increases mechanical properties. In comparison to GO and irradiation, accelerated aging produces a marked increase of residual depth due to oxidative degradation. And, the chip is generated. So accelerated aging leads to a deterioration of scratch resistance properties. Moreover, it is found that the scratch resistance of GO/UHMWPE composites is synergistically enhanced by combining GO and irradiation.

\section{Conclusions}

After irradiation and accelerated aging, the mechanical and tribological properties of GO/UHMWPE nanocomposites have been evaluated. The following conclusions can be obtained from above studies.

(1) The addition of GO to UHMWPE significantly improves the mechanical properties of UHMWPE. Gamma-irradiation further enhances the mechanical properties of GO/UHMWPE nanocomposites. 
However, accelerated aging reduces the mechanical properties of GO/UHMWPE nanocomposites.

(2) Adding GO slightly increases COF values. Irradiation further increases the COF values. But, accelerated aging significantly decreases the COF values.

(3) GO increases wear resistant properties of UHMWPE and irradiation further enhances the wear resistant properties of the composites. But, accelerated aging significantly reduces wear resistant properties of the samples.

(4) GO improves antiscratch properties. Irradiation further enhances antiscratch properties. But, accelerated aging reduces antiscratch properties.

(5) GO and irradiation can synergistically enhance the mechanical, tribological, and antiscratch properties.

\section{Competing Interests}

The authors declare that they have no competing interests.

\section{Acknowledgments}

The authors are grateful for the financial support from the National Science Foundation of China (Grant nos. 51305166, 51675232), the Natural Science Foundation of Jiangsu Province, China (BK20130143), the Fundamental Research Funds for the Central Universities (JUDCF13028), and Research and Innovation Project for College Graduates of Jiangsu Province in China (CXZZ13_0738).

\section{References}

[1] S. M. Kurtz, UHMWPE Biomaterials Handbook: Ultra-High Molecular Weight Polyethylene in Total Joint Replacement and Medical Devices, Academic Press, New York, NY, USA, 2009.

[2] L. Pruitt, "Conventional and cross-linked polyethylene properties," in Total Knee Arthroplasty, pp. 353-360, Springer, Berlin, Germany, 2005.

[3] Y. Abu-Amer, I. Darwech, and J. C. Clohisy, "Aseptic loosening of total joint replacements: mechanisms underlying osteolysis and potential therapies," Arthritis Research \& Therapy, vol. 9, supplement 1, article S6, 2007.

[4] A. V. Lombardi Jr., T. H. Mallory, B. K. Vaughn, and P. Drouillard, "Aseptic loosening in total hip arthroplasty secondary to osteolysis induced by wear debris from titanium-alloy modular femoral heads," The Journal of Bone \& Joint Surgery-American Volume, vol. 71, no. 9, pp. 1337-1342, 1989.

[5] Y.-H. Kim, J.-S. Kim, J.-W. Park, and J.-H. Joo, "Periacetabular osteolysis is the problem in contemporary total hip arthroplasty in young patients," Journal of Arthroplasty, vol. 27, no. 1, pp. 7481, 2012.

[6] A. A. Edidin, L. Pruitt, C. W. Jewett, D. J. Crane, D. Roberts, and S. M. Kurtz, "Plasticity-induced damage layer is a precursor to wear in radiation- cross-linked UHMWPE acetabular components for total hip replacement," The Journal of Arthroplasty, vol. 14, no. 5, pp. 616-627, 1999.

[7] V. Premnath, W. H. Harris, M. Jasty, and E. W. Merrill, "Gamma sterilization of UHMWPE articular implants: an analysis of the oxidation problem," Biomaterials, vol. 17, no. 18, pp. 1741-1753, 1996.

[8] L. Costa, M. P. Luda, L. Trossarelli, E. M. Brach Del Prever, M. Crova, and P. Gallinaro, "Oxidation in orthopaedic UHMWPE sterilized by gamma-radiation and ethylene oxide," Biomaterials, vol. 19, no. 7, pp. 659-668, 1998.

[9] H. Bahrami, S. Ramazani, M. Shafiee, and A. Kheradmand, "Preparation and investigation of tribological properties of ultra-high molecular weight polyethylene (UHMWPE)/ graphene oxide," Polymers for Advanced Technologies, vol. 27, no. 9, pp. 1172-1178, 2016.

[10] M. H. Al-Saleh, "Electrical and electromagnetic interference shielding characteristics of GNP/UHMWPE composites," Journal of Physics D: Applied Physics, vol. 49, no. 19, Article ID 195302, 2016.

[11] L. Xu, Y. Zheng, Z. Yan et al., "Preparation, tribological properties and biocompatibility of fluorinated graphene/ultrahigh molecular weight polyethylene composite materials," Applied Surface Science, vol. 370, pp. 201-208, 2016.

[12] Z. Xu, H. Li, and N. Sun, "Rheological investigation of creep recovery for UHMWPE or carbon nanotubes in isotactic polypropylene matrix," e-Polymers, vol. 16, no. 2, pp. 145-150, 2016.

[13] U. Mueller, J. Reinders, and J. Kretzer, "Wear performance of a prototype calcium carbonate containing pmma knee spacer," The Bone \& Joint Journal, vol. 98, supplement 9, p. 60, 2016.

[14] J. A. Puértolas and S. M. Kurtz, "Evaluation of carbon nanotubes and graphene as reinforcements for UHMWPE-based composites in arthroplastic applications: a review," Journal of the Mechanical Behavior of Biomedical Materials, vol. 39, pp. 129145,2014

[15] K. Hu, D. D. Kulkarni, I. Choi, and V. V. Tsukruk, "Graphenepolymer nanocomposites for structural and functional applications," Progress in Polymer Science, vol. 39, no. 11, pp. 1934-1972, 2014.

[16] D. Berman, A. Erdemir, and A. V. Sumant, "Graphene: a new emerging lubricant," Materials Today, vol. 17, no. 1, pp. 31-42, 2014.

[17] X. Yang, L. Li, S. Shang, and X.-M. Tao, "Synthesis and characterization of layer-aligned poly(vinyl alcohol)/graphene nanocomposites," Polymer, vol. 51, no. 15, pp. 3431-3435, 2010.

[18] W. Pang, Z. Ni, G. Chen, G. Huang, H. Huang, and Y. Zhao, "Mechanical and thermal properties of graphene oxide/ultrahigh molecular weight polyethylene nanocomposites," RSC Advances, vol. 5, no. 77, pp. 63063-63072, 2015.

[19] H. Bahrami, A. S. A. Ramazani, A. Kheradmand, M. Shafiee, and $\mathrm{H}$. Baniasadi, "Investigation of thermomechanical properties of UHMWPE/graphene oxide nanocomposites prepared by in situ ziegler-natta polymerization," Advances in Polymer Technology, vol. 34, no. 4, Article ID 21508, 2015.

[20] Y. Chen, Y. Qi, Z. Tai, X. Yan, F. Zhu, and Q. Xue, "Preparation, mechanical properties and biocompatibility of graphene oxide/ultrahigh molecular weight polyethylene composites," European Polymer Journal, vol. 48, no. 6, pp. 1026-1033, 2012.

[21] Y. F. An, Z. X. Tai, Y. Y. Qi et al., "Friction and wear properties of graphene oxide/ultrahigh-molecular-weight polyethylene composites under the lubrication of deionized water and normal saline solution," Journal of Applied Polymer Science, vol. 131, no. 1, Article ID 39640, 2014.

[22] Z. X. Tai, Y. F. Chen, Y. F. An, X. B. Yan, and Q. J. Xue, "Tribological behavior of UHMWPE reinforced with graphene 
oxide nanosheets," Tribology Letters, vol. 46, no. 1, pp. 55-63, 2012.

[23] S. Suñer, R. Joffe, J. L. Tipper, and N. Emami, "Ultra high molecular weight polyethylene/graphene oxide nanocomposites: thermal, mechanical and wettability characterisation," Composites Part B: Engineering, vol. 78, pp. 185-191, 2015.

[24] W. S. Hummers Jr. and R. E. Offeman, "Preparation of graphitic oxide," Journal of the American Chemical Society, vol. 80, no. 6, p. 1339, 1958.

[25] G. Huang, Z. Ni, G. Chen, W. Pang, and Y. Zhao, "Effects of gamma irradiation and accelerated aging on GO/UHMWPE nanocomposites," International Journal of Polymer Analysis and Characterization, vol. 21, no. 5, pp. 417-427, 2016.

[26] ISO, "Plastics and ebonite-determination of hardness by the ball indentation method," ISO 2039-73, International Organization for Standardization, 1973.

[27] S. Cao, H. Liu, S. Ge, and G. Wu, "Mechanical and tribological behaviors of UHMWPE composites filled with basalt fibers," Journal of Reinforced Plastics and Composites, vol. 30, no. 4, pp. 347-355, 2011.

[28] R. Verdejo, M. M. Bernal, L. J. Romasanta, and M. A. LopezManchado, "Graphene filled polymer nanocomposites," Journal of Materials Chemistry, vol. 21, no. 10, pp. 3301-3310, 2011.

[29] T. Ramanathan, A. A. Abdala, S. Stankovich et al., "Functionalized graphene sheets for polymer nanocomposites," Nature Nanotechnology, vol. 3, no. 6, pp. 327-331, 2008.

[30] Z. Li, R. J. Young, and I. A. Kinloch, "Interfacial stress transfer in graphene oxide nanocomposites," ACS Applied Materials and Interfaces, vol. 5, no. 2, pp. 456-463, 2013.

[31] L. Gong, I. A. Kinloch, R. J. Young, I. Riaz, R. Jalil, and K. S. Novoselov, "Interfacial stress transfer in a graphene monolayer nanocomposite," Advanced Materials, vol. 22, no. 24, pp. 26942697, 2010.

[32] M. J. Martínez-Morlanes, P. Castell, V. Martínez-Nogués, M. T. Martinez, P. J. Alonso, and J. A. Puértolas, "Effects of gamma-irradiation on UHMWPE/MWNT nanocomposites," Composites Science and Technology, vol. 71, no. 3, pp. 282-288, 2011.

[33] N. Shibata, S. M. Kurtz, and N. Tomita, "Recent advances of mechanical performance and oxidation stability in ultrahigh molecular weight polyethylene for total joint replacement: highly crosslinked and $\alpha$-tocopherol doped," Journal of Biomechanical Science and Engineering, vol. 1, no. 1, pp. 107-123, 2006.

[34] L. F. Dumée, C. Feng, L. He et al., "Single step preparation of meso-porous and reduced graphene oxide by gamma-ray irradiation in gaseous phase," Carbon, vol. 70, pp. 313-318, 2014.

[35] Y. Qiu, Z. Wang, A. C. E. Owens et al., "Antioxidant chemistry of graphene-based materials and its role in oxidation protection technology," Nanoscale, vol. 6, no. 20, pp. 11744-11755, 2014.

[36] B. J. Briscoe, P. D. Evans, E. Pelillo, and S. K. Sinha, "Scratching maps for polymers," Wear, vol. 200, no. 1-2, pp. 137-147, 1996.

[37] K.-S. Kim, H.-J. Lee, C. Lee et al., "Chemical vapor depositiongrown graphene: the thinnest solid lubricant," ACS Nano, vol. 5, no. 6, pp. 5107-5114, 2011.

[38] J. De Boer, H.-J. Van Den Berg, and A. J. Pennings, "Crosslinking of ultra-high molecular weight polyethylene in the oriented state with dicumylperoxide," Polymer, vol. 25, no. 4, pp. 513-519, 1984.

[39] A. Dasari, Z.-Z. Yu, and Y.-W. Mai, "Fundamental aspects and recent progress on wear/scratch damage in polymer nanocomposites," Materials Science and Engineering R: Reports, vol. 63, no. 2, pp. 31-80, 2009.
[40] M. Wong, G. T. Lim, A. Moyse, J. N. Reddy, and H.-J. Sue, "A new test methodology for evaluating scratch resistance of polymers," Wear, vol. 256, no. 11-12, pp. 1214-1227, 2004.

[41] R. D. K. Misra, R. Hadal, and S. J. Duncan, "Surface damage behavior during scratch deformation of mineral reinforced polymer composites," Acta Materialia, vol. 52, no. 14, pp. 43634376, 2004.

[42] K.-Y. Shin, J.-Y. Hong, S. Lee, and J. Jang, "Evaluation of antiscratch properties of graphene oxide/polypropylene nanocomposites," Journal of Materials Chemistry, vol. 22, no. 16, pp. 78717879, 2012. 

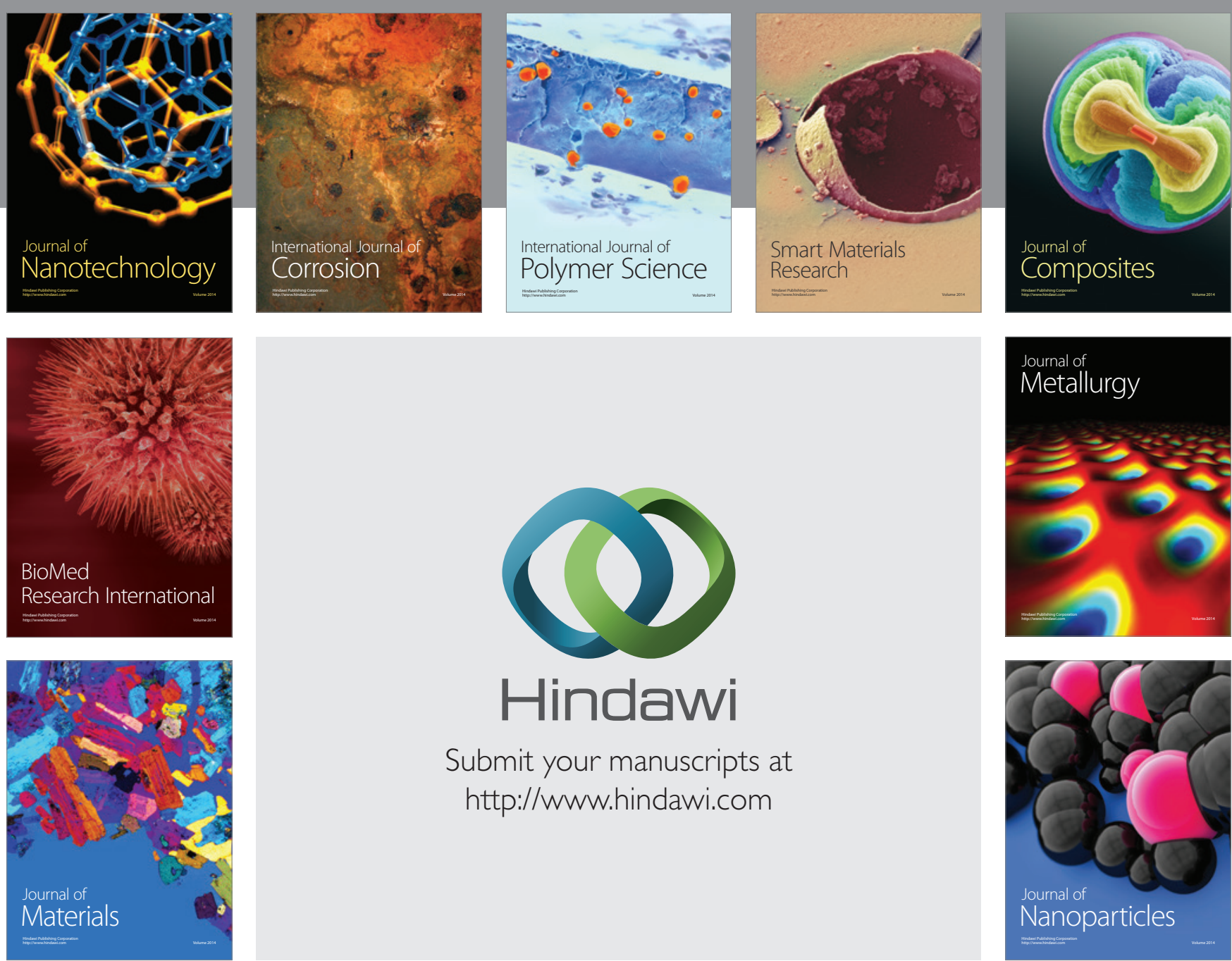

\section{Hindawi}

Submit your manuscripts at

http://www.hindawi.com

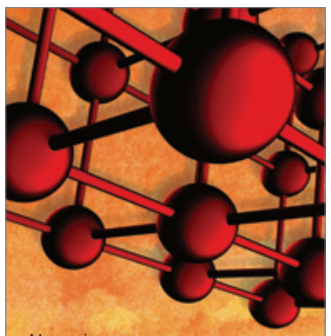

Materials Science and Engineering
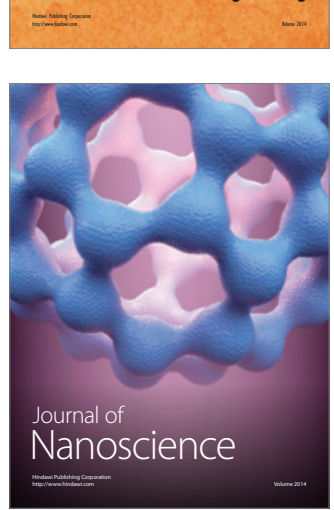
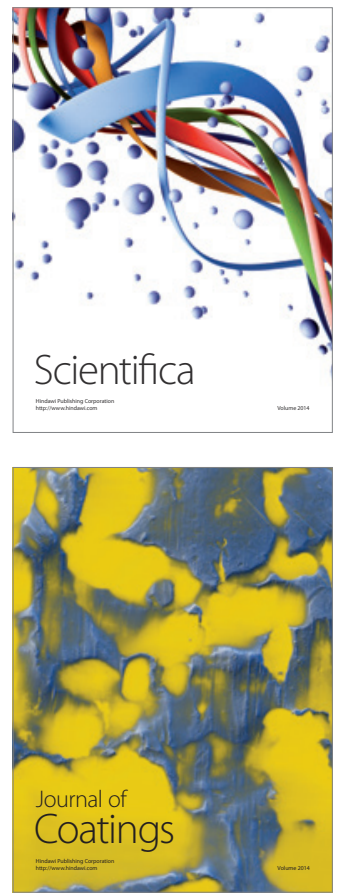
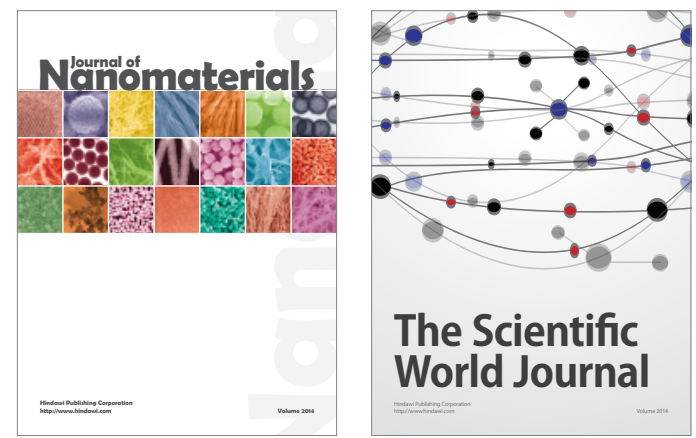

The Scientific World Journal
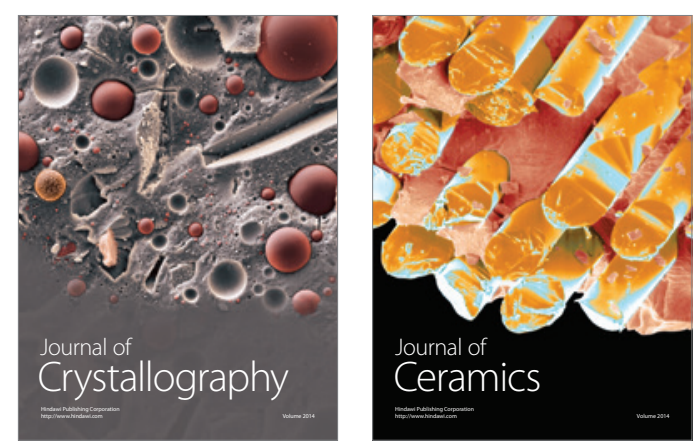
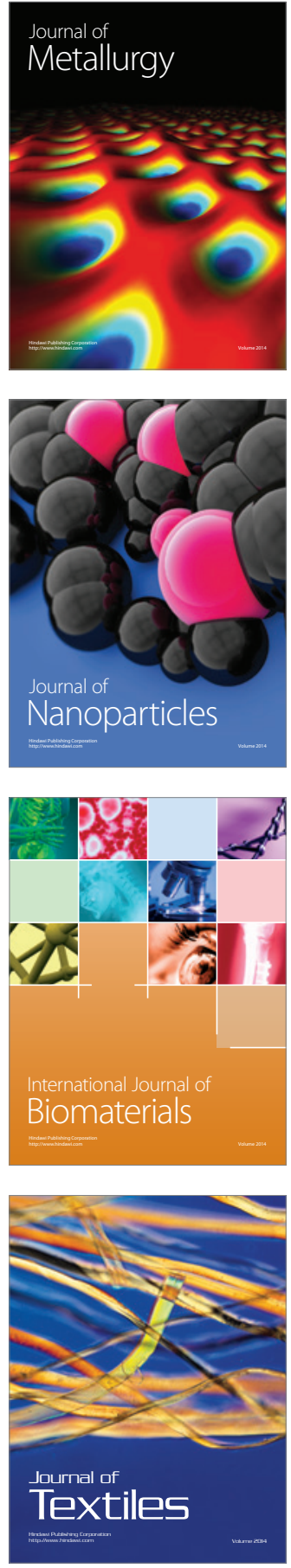